\title{
Irrigated Soybean Leaf Photosynthesis in the Humid Subtropical Midsouth
}

\author{
H. Arnold Bruns \\ Crop Production Systems Research Unit, USDA-ARS, MSA, P.O. Box 350, 141 Research Road, Stoneville, MS 38776, USA \\ Correspondence should be addressed to H. Arnold Bruns; arnold.bruns@ars.usda.gov
}

Received 19 August 2013; Revised 20 November 2013; Accepted 10 December 2013; Published 23 January 2014

Academic Editor: Kent Burkey

Copyright (C) $2014 \mathrm{H}$. Arnold Bruns. This is an open access article distributed under the Creative Commons Attribution License, which permits unrestricted use, distribution, and reproduction in any medium, provided the original work is properly cited.

\begin{abstract}
Photosynthesis (CER $\left(\mu \mathrm{mol} \mathrm{CO} \mathrm{Cm}_{\text {leaf area }}^{-2} \mathrm{~s}^{-1}\right)$ ), stomatal conductance $\left(g_{\mathrm{sw}}\right)$, and intercellular $\left[\mathrm{CO}_{2}\right]\left(C_{i}\right)$ of soybean $($ Glycine max L. Merr.) grown using the early soybean production system (ESPS) of the midsouth were determined. Three irrigated cultivars were grown using ESPS on Bosket (Mollic Hapludalfs) and Dundee (Typic Endoaqualf) soils in 2011 and 2012 at Stoneville, MS. Single leaf CER, $g_{\mathrm{sw}}$, and $C_{i}$ were determined at growth stages R3, R4, and R5 using decreasing photosynthetic photon flux densities (PPFD, $\mu \mathrm{mol} \mathrm{m} \mathrm{s}^{-1}$ ) beginning at 2000 PPFD and decreasing by 250 PPFD increments to 250 PPFD. Photosynthesis changes fit a quadratic polynomial for all fixed variables and range from $\sim 6.0$ and 9.0 CER at 250 PPFD and 22.0 to 28.0 CER at 2000 PPFD. No cultivar differences in CER, $g_{\mathrm{sw}}$, or $C_{i}$ were noted at any growth stage or site either year. In 2012, CER, $g_{\mathrm{sw}}$, and $C_{i}$ were lower when measured at R5 than the two previous growth stages, which was not observed in 2011. The R5 sampling in 2012 had accumulated 39 to 70 more growing degree units at $10^{\circ} \mathrm{C}$ base temperature (GDU 10's) than in 2011 and were likely more mature. Increased soybean yields from ESPS appear not to result from higher leaf CER.
\end{abstract}

\section{Introduction}

Adoption of the early soybean (Glycine max L. Merr.) production system (ESPS) is nearly complete throughout the humid subtropical lower Mississippi River Valley and has become the standard production practice. Except for a few hectares seeded in double-crop systems following wheat (Triticum aestivum L.), most soybean crops in the Mississippi Delta are seeded before 1 May with cultivars in the maturity group (MG) 4.0 to MG 5.5 range. Seldom are any sizeable hectares seeded to cultivars later than MG 5.5 which were among the most common ones grown in the midsouth prior to 1995 [1].

Prior to development of the ESPS, soybean production in the midsouth involved seeding cultivars of the MG 5.0 to MG 7.0 range between 15 May and 10 June resulting in reproductive growth occurring through July to mid-August. This is typically a droughty period with maximum daily temperatures regularly in excess of $30^{\circ} \mathrm{C}$ which is the established optimum temperature for soybean growth [2]. Seed yields, under the original production system when irrigated, seldom exceeded $3400 \mathrm{~kg} \mathrm{ha}^{-1}$ and without irrigation often failed to exceed $1300 \mathrm{~kg} \mathrm{ha}^{-1}$ [1]. Research conducted by Heatherly
[3] and Bowers [4] during the mid of 1980's demonstrated that planting MG 4 and MG 5 cultivars in April produced higher yields than the same cultivars seeded in May under both irrigated and nonirrigated production systems. With the adoption of ESPS state average soybean yields in Mississippi alone have nearly doubled from $1411 \mathrm{~kg} \mathrm{ha}^{-1}$ in 1980 to $2755 \mathrm{~kg} \mathrm{ha}^{-1}$ in 2011 [5].

As with all crops, soybean yield is the result of the net accumulation of organic compounds assimilated through photosynthesis. Research on soybean photosynthesis conducted during the 1950's and 1960's found that several cultivars grown at that time became light saturated at approximately 450 to $870 \mu \mathrm{mol} \mathrm{m}^{-2} \mathrm{~s}^{-1}$ photosynthetic photon flux density (PPFD) [6-9]. However, much of those data were collected from plants grown in a greenhouse or other artificial environment. Beuerlein and Pendleton [10] using attached leaves of a field grown MG 3 soybean cultivar determined light saturation occurred at about $1950 \mu \mathrm{mol} \mathrm{m}^{-2} \mathrm{~s}^{-1} \mathrm{PPFD}$ for plants growing in a normal canopy. Dornhoff and Shibles [8] reported that net photosynthesis of several soybean cultivars began to increase with the onset of pod filling. 
Buttery et al. [11] reported a positive correlation between leaf CER during reproductive growth and seed yields of several MG 2 soybean cultivars. High seed yields in MG 5, 6 , and 7 cultivars were determined to be associated with high photosynthetic capacity of the entire crop canopy integrated over the seed-fill period [12].

Much of the information on the response of soybean photosynthesis to changing light levels however is dated, having been published prior to 1985, with cultivars that are no longer in production, using less portable and sophisticated instrumentation than is now available. Also, despite the adoption of ESPS in much of the midsouth, which is a humid subtropical environment, little or no information on CER and related physiological events of the MG 4 and 5 cultivars grown in this system is available. The objective of this experiment was to determine how some of the basic physiological processes (CER, $g_{\mathrm{sw}}$, and $C_{i}$ ) of MG 4 and MG 5 soybean cultivars at growth stages R3, R4, and R5 as defined by Ritchie et al., [13], are affected when grown in the ESPS. The experiment was conducted on two different soils commonly used for irrigated soybean production and utilized one of the modern portable instruments that allows simultaneous measurements of such parameters in field grown plants.

\section{Materials and Methods}

The experiment was conducted at two sites near Stoneville, MS, in 2011 and 2012. One was a Bosket very fine sandy loam and the other Dundee silty clay. The experimental design used for that study was a randomized complete block replicated three times. Experimental units were one of three soybean cultivars, Asgrow (Monsanto; St Louis, MO) AG4303 (MG 4.3), Pioneer (DuPont; Johnston, IA) $94 \mathrm{~B} 73$ (MG 4.8), and Asgrow AG5503 (MG 5.5). Plots were eight $12 \mathrm{~m}$ rows seeded in a twin-row configuration planted with a Monosem NG3 (Monosem; Edwardsville, KS). Each row of the twin-row unit was spaced $25 \mathrm{~cm}$ apart and centered on $102 \mathrm{~cm}$ between units. Seeding was at a rate of 30 seed $\mathrm{m}^{-2}$ and occurred on 14 April 2011 at both locations, 23 April 2012 on the Dundee silty clay and 25 April, 2012 on the Bosket sandy loam. The previous crop at both sites in 2011 was corn (Zea mays L.) and soybean in 2012.

Seedbeds were prepared each season by first bedding the fields into $40 \mathrm{~cm}$ high ridges spaced $102 \mathrm{~cm}$ apart then harrowing them to $40 \mathrm{~cm}$ wide seedbeds just prior to planting. Weed control was achieved by combinations of metolachloro and glyphosate applied according to label directions for soybean crops grown in Mississippi. Furrow irrigations of approximately $25.0 \mathrm{~mm}$ each were applied every $10 \mathrm{~d}$ or $10 \mathrm{~d}$ after a rain event of $25.0 \mathrm{~mm}$ or more on the Dundee silty clay site beginning at growth stage $\mathrm{V} 4$ and continuing until R7. Irrigations on the Bosket very fine sand were required on a $7 \mathrm{~d}$ schedule due to the poor water holding capacity of the soil. Plots were harvested upon maturity and yields were recorded. Total plant leaf area (LA) at R4, a period defined as when soybean LA is at maximum [14], was estimated by harvesting four plants at random in the second and seventh rows of each
TABLE 1: Sampling dates, days after planting (DAP), growing degree units $10^{\circ} \mathrm{C}$ base (GDU 10's), of leaf photosynthesis measurements of three soybean cultivars (94B73, AG4303, and AG5503) grown using the early soybean production system on a Bosket sandy loam and Dundee silty clay at Stoneville, MS, in 2011 and $2012^{\dagger}$.

\begin{tabular}{lccc}
\hline Growth stage & Sampling date & DAP & GDU 10 \\
\hline \multicolumn{4}{c}{ Bosket } \\
R3 & $6 / 20 / 2011$ & 68 & 955.3 \\
R4 & $7 / 7 / 2011$ & 83 & 1233.1 \\
R5 & $7 / 19 / 2011$ & 97 & 1381.6 \\
R3 & $7 / 5 / 2012$ & 73 & 1055.5 \\
R4 & $7 / 20 / 2012$ & 88 & 1299.7 \\
R5 & $7 / 27 / 2012$ & 95 & 1420.6 \\
\hline & Dundee & & \\
R3 & $7 / 17 / 2011$ & 74 & 849.7 \\
R4 & $7 / 6 / 2011$ & 84 & 1161.1 \\
R5 & $7 / 20 / 2011$ & 98 & 1398.3 \\
R3 & $7 / 6 / 2012$ & 74 & 1072.8 \\
R4 & $7 / 19 / 2012$ & 87 & 1283.3 \\
R5 & $7 / 30 / 2012$ & 98 & 1468.1 \\
\hline
\end{tabular}

${ }^{\dagger}$ Official weather observations acquired from the Mississippi State University's Delta Research and Extension Center, Stoneville, MS.

subplot, striping the leaves and measuring their area using a Li-Cor model LI 3100C leaf area meter. Established plants per $\mathrm{m}^{-2}$ were determined at growth stage V4 by selecting randomly, a meter segment in the middle two rows of the plot and counting the number of plants. These data were then combined to estimate leaf area index (LAI) for the plot.

Photosynthesis, $g_{\mathrm{sw}}$, and $C_{i}$ data were collected on the most recent fully expanded leaf of three randomly selected plants in each plot at growth stages R3, R4, and R5. Sampling dates were chosen using Zhang et al. [15] as a guide for approximate dates after planting when all three cultivars would be at the predetermined growth stage. The specific dates, days after planting (DAP), and growing degree units at a base of $10^{\circ} \mathrm{C}$ are presented in Table 1 . Photosynthesis was determined using a Li-Cor LI-6400XT portable photosynthesis system (Li-Cor Biosciences; Lincoln, NE) with a 6400-02(B) LED light source attached to the leaf chamber. Temperature in the leaf chamber was set at $22.5^{\circ} \mathrm{C}$. Carbon dioxide levels in the leaf chamber were controlled by using $\mathrm{CO}_{2}$ cartridge and fixed flow rate of $500 \mu \mathrm{mol} \mathrm{s}^{-1}$. Carbon dioxide concentration within the leaf chamber was fixed at $355 \mu \mathrm{mol} \mathrm{mol}^{-1}$. This level had been predetermined by numerous air samples taken at various locations near the experimental sites just prior to collecting data in 2011 and kept at this level throughout the study for comparison purposes. The location of the experiment was in a comparatively sparsely populated area with no heavy industry within $200 \mathrm{~km}$ to influence local ambient $\mathrm{CO}_{2}$ levels.

Light response curves for individual leaves were developed by initially setting the intensity of the LED light source at an indicated $2000 \mu \mathrm{mol} \mathrm{m}^{-2} \mathrm{~s}^{-1}$ PPFD, allowing the CER value to stabilize, record the CER, $g_{\mathrm{sw}}$, and $C_{i}$ levels, and then to lower the PPFD by $250 \mu \mathrm{mol} \mathrm{m}^{-2} \mathrm{~s}^{-1}$ increments, and 
TABLE 2: Predictive regression equations of mean photosynthesis rates (CER $\left(\mu \mathrm{mol} \mathrm{CO} \mathrm{m}^{-2} \mathrm{~s}^{-1}\right)$ ) versus PPFD of recently matured leaflets for three irrigated soybean cultivars (94B73, AG4303, and AG5503) at growth stages R3, R4, and R5 grown using the early soybean production system on a Bosket sandy loam and Dundee silty clay at Stoneville, MS, in 2011 and $2012^{\dagger}$.

\begin{tabular}{cccccc}
\hline Year & Growth stage & Bosket & $R^{2}$ & Dundee \\
\hline 2011 & R3, R4, and R5 & $y=-0.000006 x^{2}+0.0235 x+2.611$ & 0.9717 & $y=-0.00006 x^{2}+0.0201 x+4.5398$ & 0.9732 \\
& R3 and R4 & $y=-0.00006 x^{2}+0.0214 x+5.3225$ & 0.9818 & $y=-0.00006 x^{2}+0.0199 x+7.4126$ & 0.9905 \\
2012 & R5 & $y=-0.0006 x^{2}+0.0156 x+4.2831$ & 0.9879 & $y=-0.00006 x^{2}+0.0199 x+1.0303$ & 0.9905 \\
\hline
\end{tabular}

${ }^{\dagger}$ Calculated from the means of 3 plants, 3 cultivars, and 3 replications at each growth stage.

again allowing CER level to stabilize before recording the data, until an indicated PPFD level of $250 \mu \mathrm{mol} \mathrm{m}^{-2} \mathrm{~s}^{-1}$ was achieved for a total of eight measurements per leaf. Observed PPFD levels generated by the LED light source were simultaneously recorded with each physiological measurement. Data collection was done between 8:30 am and 11:30 am CST. All data were collected within $48 \mathrm{~h}$ of an irrigation or rain event greater than $25.0 \mathrm{~mm}$ to minimize any effects that drought stress might have on the plants' water status. Data collection also was done on days with $30 \%$ or less cloud cover to minimize the negative effect that low natural light intensities have upon $g_{\text {sw }}$. Data on growing degree units at $10^{\circ} \mathrm{C}$ base temperature (GDU 10's) were calculated from weather data collected at the Delta Research and Extension Center of Mississippi State University and are shown in Table 1.

Data on LAI at growth stage R4 were analyzed using the PROC MIXED procedure of the statistical analysis system (Cary, NC) with the level for significance set at $P \leq 0.05$. Data were pooled across locations and years after individual analysis of sites and years showed no significant differences in LAI among cultivars or environments. Analyses on all other data were also conducted using the PROC MIXED procedure of the statistical analysis system with the level for significance set at $P \leq 0.05$. A general linear mixed model was used to perform the ANOVA for each year at each location which was analyzed as a split-split plot with cultivar as a whole plot, growth stage as a subplot, and indicated PPFD as a subsub plot. Replication, growth stage, and indicated PPFD were considered classification effects with observed PPFD considered as a continuous effect. Random effects were rep $\mathrm{x}$ cultivar, rep $\mathrm{x}$ growth stage (cultivar) and cultivar $\mathrm{x}$ growth stage $\mathrm{x}$ indicated PPFD. Predicted CER levels were calculated for each indicated PPFD at both locations both years. After tests were conducted to evaluate several curvilinear forms using both polynomials and logs, it was determined that quadratic polynomials provided the best fit for relationships of the data analyzed. Regression analyses were conducted on both observed and predicted CER rates at the various observed and indicated PPFD values, respectively. Regression analyses were also conducted on $g_{\mathrm{sw}}$ and $C_{i}$ levels versus the observed PPFD levels.

\section{Results and Discussion}

Analysis of variance of LAI data at R4 at both sites and both years was found not to differ among cultivars, sites, or years. The mean LAI at R4 for this experiment was 3.6 which was previously established, by Higley [14], as being within the critical range of LAI is necessary to achieve maximum soybean yields. Statistical analyses of all other data collected in this experiment showed no significant differences among cultivars at any particular growth stage at either site in 2011 or 2012 and therefore data were pooled for each growth stage at each site both years.

Analysis of CER in this experiment demonstrated that soybean response to decreasing PPFD was best represented by quadratic polynomials (Figures $1(\mathrm{~b})-2$ (b) and Table 2 ). These data are similar to previously reported light response curves developed for the species in other environments $[10$, 16-18]. Single leaf CER levels for MG 4 and MG 5 cultivars grown in this experiment did not become light-saturated at an indicated 2000 PPFD at either site or growth stage except possibly at R3 in 2012 on the Bosket sandy loam (Figures 1(a) and 2(a)). Calculated predictive CER values for both sites and at all growth stages in both years did not predict that light saturation would occur at 2000 actual PPFD (Figures 1(b) and 2(b) and Table 2). Bowes et al. [16] suggested that soybean appears to develop sufficient, but not excessive, capacity to utilize the maximum light available while Beuerlein and Plendleton [10] concluded that soybean appears to acclimate to the light environment it grows in. The artificial light source used in this experiment, when set at 2000 PPFD, probably did not attain the maximum light intensity the plants had been acclimated to receiving in the field and thus light saturation was not observed in most of this experiment.

Both observed and predicted CER's at both sites and all growth stages in 2011 showed rates at indicated 250 PPFD to be between approximately 6.0 and $9.0 \mu \mathrm{mol} \mathrm{CO}_{2} \mathrm{~m}_{\text {leaf area }}^{-2} \mathrm{~s}^{-1}$ and 22.0 to $28.0 \mu \mathrm{mol} \mathrm{CO} \mathrm{CO}_{\text {leaf area }}^{-2} \mathrm{~s}^{-1}$ at indicated 2000 PPFD (Figures 1(a)-1(b)). Comparisons of these data with previous research show CER levels in this study to be similar to those reported earlier. Long and Hällgren [18] using an instrument like the one used in this experiment measured CER in soybean at approximately 250 PPFD to be slightly < $8.0 \mu \mathrm{mol} \mathrm{CO} \mathrm{C}_{\text {leaf area }}^{-2} \mathrm{~s}^{-1}$ and $>24.0 \mu \mathrm{mol} \mathrm{CO} \mathrm{CO}_{\text {leaf area }}^{-2} \mathrm{~s}^{-1}$ at a PPFD of slightly less than 2000. Beuerlein and Pendleton [10] observed a range of 20.0 to $33.0 \mu \mathrm{mol} \mathrm{CO} \mathrm{Cm}_{\text {leaf area }} \mathrm{s}^{-1}$ in a normal canopy of soybean plants (cv. Wayne) grown at light levels equivalent to full unobstructed sunlight. Dornhoff and Shibles [8], reported mean CER levels of several soybean cultivars exposed to $\mathrm{CO}_{2}$ levels of 300 or $386 \mu \mathrm{mol} \mathrm{mol}^{-1}$ to range from 35.2 to $38.8 \mu \mathrm{mol} \mathrm{CO} \mathrm{m}_{\text {leaf area }}^{-2} \mathrm{~s}^{-1}$.

In 2011, for the Bosket site, one quadratic equation adequately described the predicated rate of CER change with 


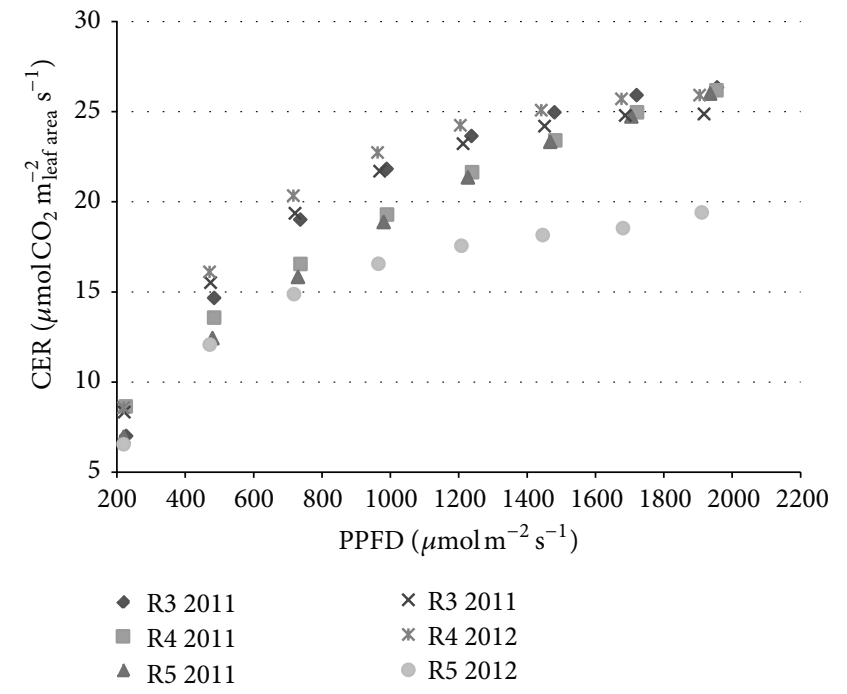

(a)

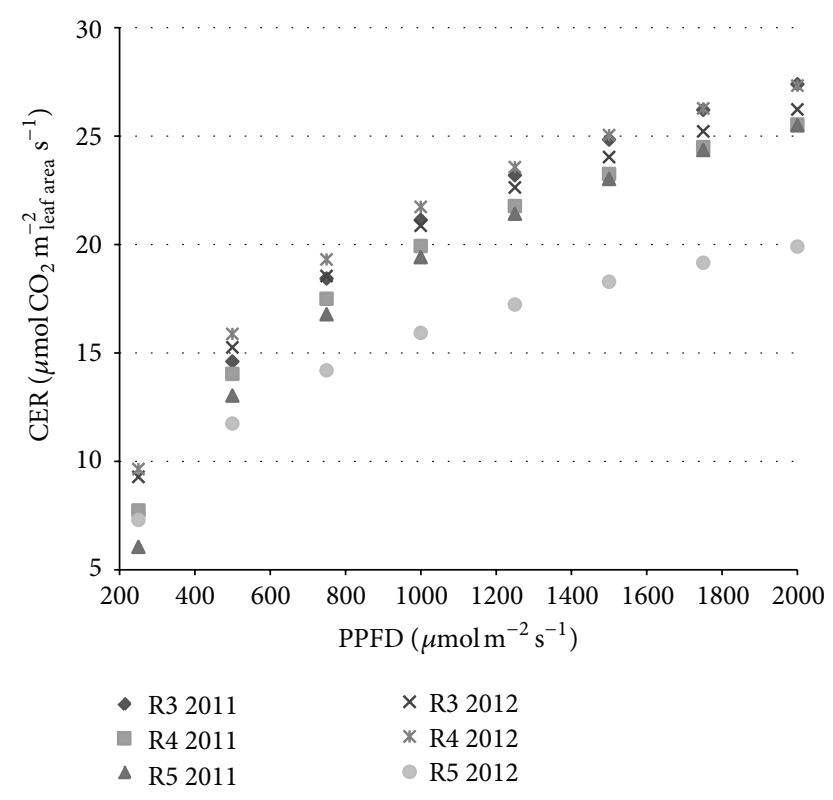

(b)

FIGURE 1: (a) Mean CER of three irrigated soybean cultivars (94B73, AG4303, and AG5503) exposed to declining PPFD levels at growth stages R3, R4, and R5 grown on a Bosket sandy loam at Stoneville, MS, in 2011 and 2012. (b) Mean predicted CER of three irrigated soybean cultivars (94B73, AG4303, and AG5503) under different PPFD levels at growth stages R3, R4, and R5 and grown on a Bosket sandy loam at Stoneville, MS, in 2011 and 2012.

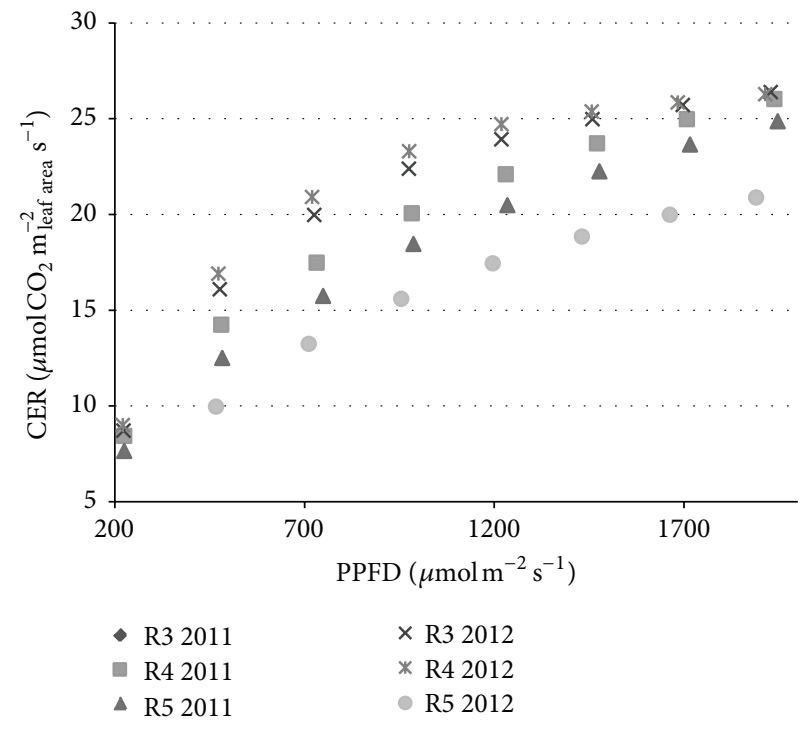

(a)

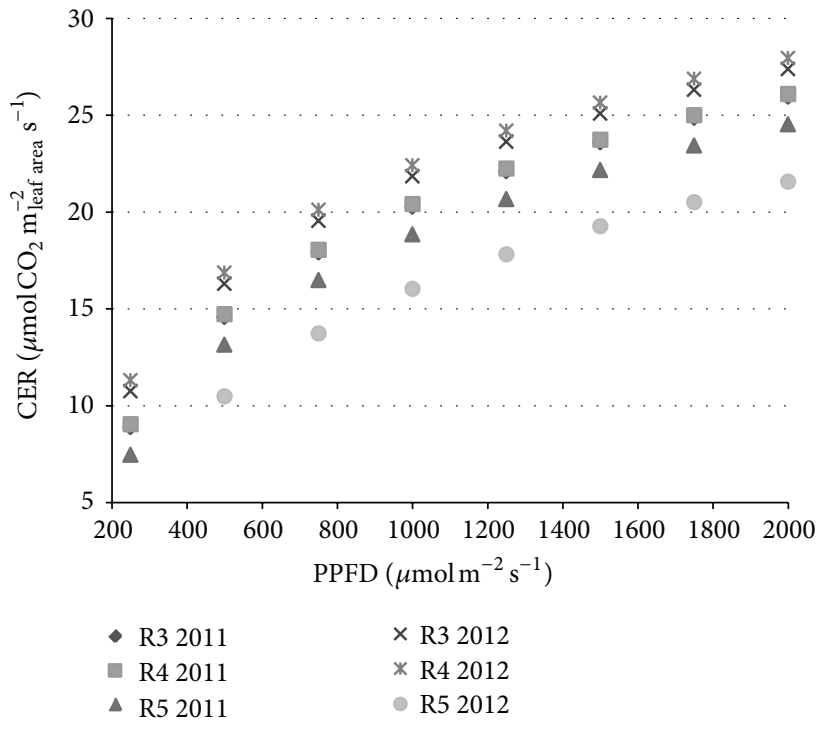

(b)

Figure 2: (a) Mean CER of three irrigated soybean cultivars (94B73, AG4303, and AG5503) exposed to declining PPFD levels at growth stages R3, R4, and R5 grown on a Dundee silty clay at Stoneville, MS, in 2011 and 2012. (b) Mean predicted CER of three irrigated soybean cultivars (94B73, AG4303, and AG5503) under different PPFD levels at growth stages R3, R4, and R5 grown on a Dundee silty clay at Stoneville, MS, in 2011 and 2012.

changing PPFD for all three growth stages (Table 2). The same was true for the Dundee site. However, in 2012, CER data at R5 was significantly lower at all observed PPFD levels than at R3 and R4 at both sites (Figures 1(a) and 2(b)). The predictive equations and subsequent predicted CER's at R5 for both sites in 2012 were different as well, from those calculated for the earlier growth stages (Figures 1(b) and 2(b) and Table 2). In 2012, at the Bosket site, the plants had accumulated approximately 39 GDU 10's more by R5 than in 2011 (Table 1). At the Dundee site, the increase in GDU 10's at R5 in 2012 over 2011 was approximately 70 units. The days after planting (DAP) in which CER at R5 were collected at 


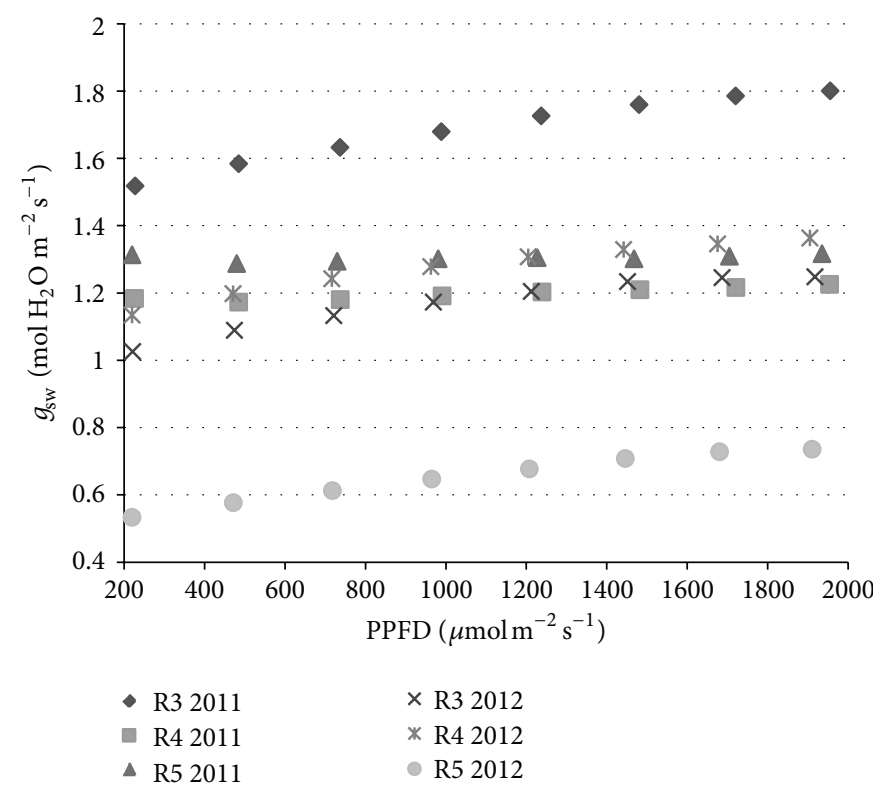

(a)

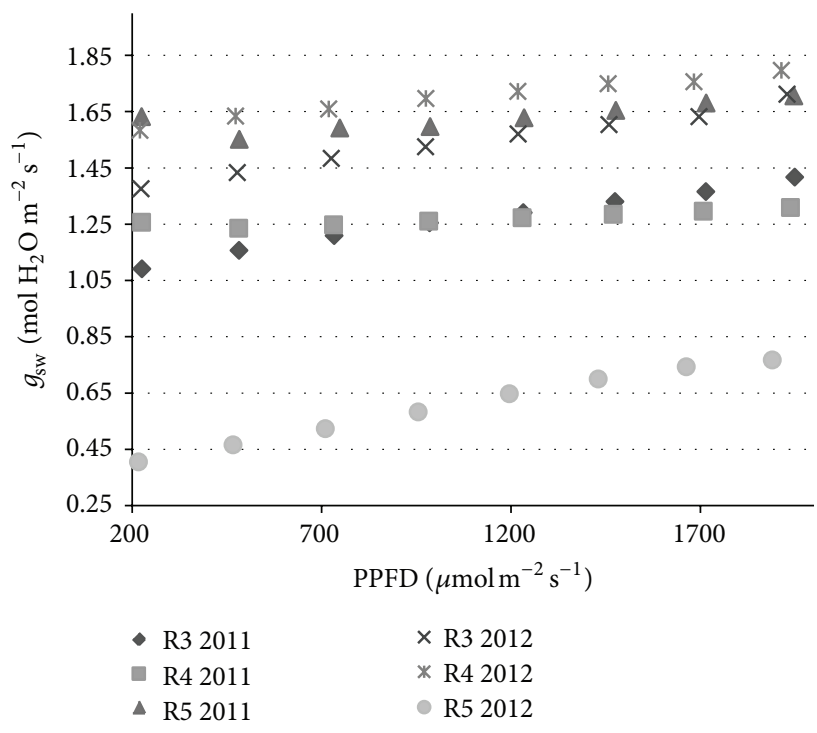

(b)

FIGURE 3: (a) Mean stomatal conductance $\left(g_{\text {sw }}\right)$ of three irrigated soybean cultivars (94B73, AG4303, and AG5503) exposed to declining PPFD levels at growth stages R3, R4, and R5 grown on a Bosket sandy loam at Stoneville, MS, in 2011 and 2012. (b) Mean stomatal conductance ( $g_{\text {sw }}$ ) of three irrigated soybean cultivars (94B73, AG4303, and AG5503) exposed to declining PPFD levels at growth stages R3, R4, and R5 grown on a Dundee silty clay at Stoneville, MS, in 2011 and 2012.

TABLE 3: Regression equations of stomatal conductance $\left(g_{\mathrm{sw}}\right)$ versus PPFD levels of recently mature leaflets of irrigated soybean at growth stages R3, R4, and R5 grown using the Early Soybean Production System at Stoneville, MS, in 2011 and $2012^{\dagger}$.

\begin{tabular}{lcccc}
\hline Site & GS & 2011 & $R^{2}$ & 2012 \\
2011 & $R^{2}$ \\
Bosket & R3 & $y=0001.6 x+1.50$ & 0.97 & $y=001.3 x+1.03$ \\
& R4 & $y=00002.8 x+1.17$ & 0.90 & $y=0001.3 x+1.13$ \\
& R5 & $y=000009.4 x+1.29$ & 0.21 & $y=0001.2 x+0.52$ \\
Dundee & R3 & $y=0001.8 x+1.07$ & 0.99 & $y=0001.8 x+1.34$ \\
& R4 & $y=00003.9 x+1.23$ & 0.84 & $y=0001.2 x+1.57$ \\
\hline
\end{tabular}

${ }^{\dagger}$ Calculated from the means of 3 plants, 3 cultivars (94B73, AG 4303, and AG 5503), and 3 replications.

the Bosket site were $2 \mathrm{~d}$ later in 2011 (97 d) than in 2012 (95 d) while they were the same ( $98 \mathrm{~d}$ ) both years at the Dundee site. It appears from these data that accumulated GDU 10's are likely an important factor in determining a soybean plant's physiological development in the midsouth similar to what has been reported for the Northern Great Plains Kandel and Akyuz [19].

Stomatal conductance $\left(g_{\mathrm{sw}}\right)$ declined slightly as PPFD levels were reduced during most samplings of individual leaflets (Figure 3(a), 3(b) and Table 3). This was observed at all growth stages in both sites and years. Slopes $(\beta)$ of linear equations for individual sampling periods over both sites and both years ranged from 0.0000094 to 0.00023 (Table 3). Significant differences $(P>|t| \leq 0.05)$, for individual slopes, were noted for R3 versus R4 and R3 versus R5 but not R4 versus R5 at both the Bosket and Dundee sites in
2011 (Table 4). Stomatal conductance for plants at the Bosket site declined slightly at R3 both in 2011 and 2012 as PPFD decreased during sampling, while at R4 and R5 in 2011 the change was barely detectable (Figure 3(a)). At this site, in 2012, no difference was observed in the slopes of the $g_{\text {sw }}$ 's (Figure 3(a) and Tables 3 and 4). However, the intercepts were $1.03,1.13$, and 0.52 for $\mathrm{R} 3, \mathrm{R} 4$, and $\mathrm{R} 5$, respectively, which further demonstrates the probable effects of advanced maturity on the lower CER levels observed at R5 as previously discussed.

Stomatal conductance at R3 for the Dundee site in 2011 declined as PPFD was reduced during sampling while essentially no changes in $g_{\mathrm{sw}}$ were noted for the later growth stages (Figure 3(b)). The $g_{\text {sw }}$ at R5 in 2011 for the Dundee site was considerably higher than at R3 and R4, while in 2012 $g_{\text {sw }}$ was much lower at R5 than the previous two growth 


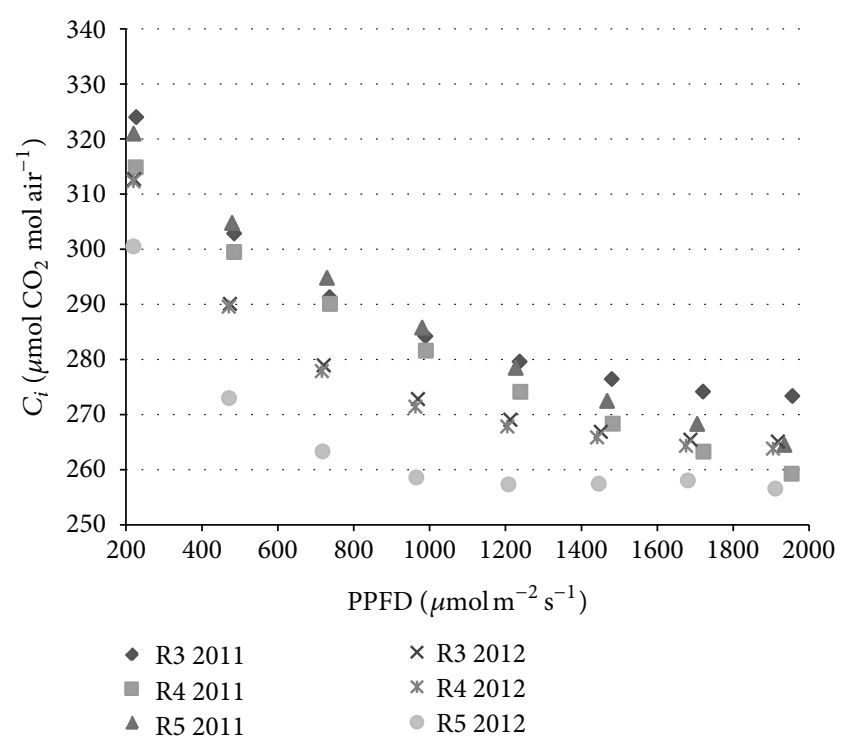

(a)

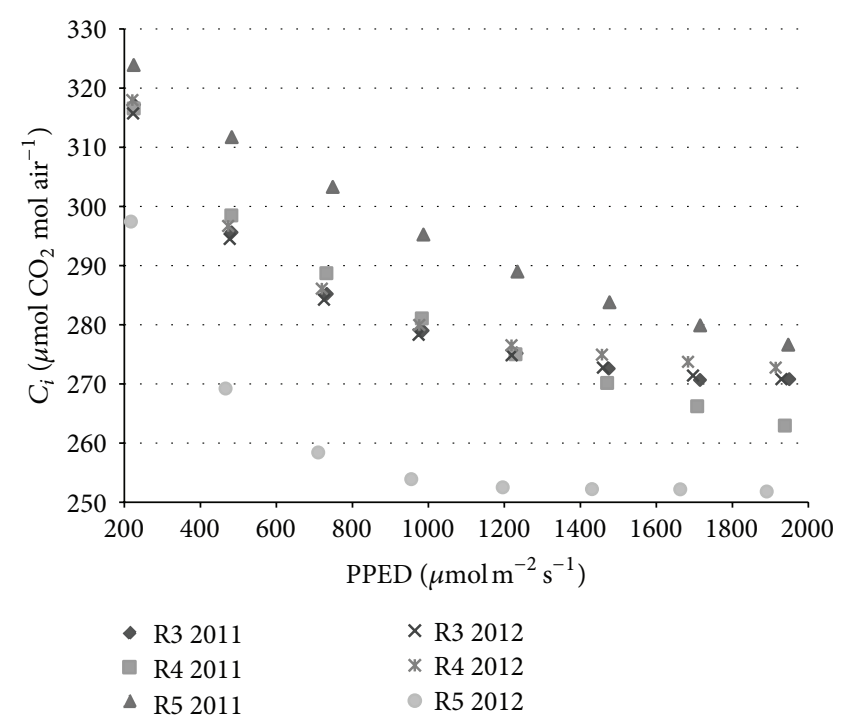

(b)

Figure 4: (a) Mean intercellular $\left[\mathrm{CO}_{2}\right] C_{i}$ of three irrigated soybean cultivars (94B73, AG4303, and AG5503) exposed to declining PPFD levels at growth stages R3, R4, and R5 grown on a Bosket sandy loam at Stoneville, MS, in 2011 and 2012. (b) Mean intercellular [CO $\mathrm{CO}_{2}$ ) of three irrigated soybean cultivars (94B73, AG4303, and AG5503) exposed to declining PPFD levels at growth stages R3, R4, and R5 grown on a Dundee silty clay at Stoneville, MS, in 2011 and 2012.

TABLE 4: Comparisons of slopes for stomatal conductance $\left(g_{\text {sw }}\right)$ versus PPFD of recently mature leaflets of irrigated soybean at growth stages R3, R4, and R5 grown using the Early Soybean Production System at Stoneville, MS, in 2011 and $2012^{\dagger}$.

\begin{tabular}{lccc}
\hline Comparison & $\begin{array}{c}\text { Bosket } \\
P>|t|\end{array}$ & Comparison & $\begin{array}{c}\text { Dundee } \\
P>|t|\end{array}$ \\
\hline 2011 & \multicolumn{3}{c}{012} \\
R3 versus R4 & 0.0007 & R3 versus R4 & 0.0021 \\
R3 versus R5 & 0.0001 & R3 versus R5 & 0.0129 \\
R4 versus R5 & 0.6508 & R4 versus R5 & 0.5497 \\
2012 & \multicolumn{3}{|}{0.1699} \\
R3 versus R4 & 0.9658 & R3 versus R4 & 0.3629 \\
R3 versus R5 & 0.8128 & R3 versus R5 & 0.3629 \\
R4 versus R5 & 0.8468 & R4 versus R5 & 0.0237 \\
\hline
\end{tabular}

${ }^{\dagger}$ Calculated from the means of 3 plants, 3 cultivars (94B73, AG 4303, and AG 5503), and 3 replications.

stages. As stated earlier, at this site, data were collected 98 DAP in both years, with irrigation being applied at the time of sampling. The only measured difference between these two sampling periods was the greater GDU 10's accumulated in 2012 compared to 2011 leaving probable differences in plant maturity between years as the most logical explanation for the observed difference in $g_{\mathrm{sw}}$ at this growth stage.

Intercellular $\mathrm{CO}_{2}$ concentrations $\left(C_{i}\right)$ increased with decreases in PPFD (Figures 4(a) and 4(b)). At the Bosket site, in 2011, $C_{i}$ did not differ among the growth stages as light levels decreased (Figure 4(a)). In 2012, at this site, $C_{i}$ was less $(P \leq 0.05)$ at R5 at all PPFD's than the previous two growth stages. At the Dundee site, no differences in $C_{i}$ were observed
TABLE 5: Seed yields of three irrigated soybean cultivars grown in $25 \mathrm{~cm}$ twin rows spaced $102 \mathrm{~cm}$ apart on two soils at Stoneville, MS, in 2011 and $2012^{\dagger}$.

\begin{tabular}{llrlr}
\hline \multirow{2}{*}{ Cultivar } & \multicolumn{2}{c}{ Bosket $^{\ddagger}$} & \multicolumn{2}{c}{ Dg handee $^{\S}$} \\
& 2011 & 2012 & 2011 & 2012 \\
\hline 94 B73 & 3717 & 3409 & 3083 & 3646 \\
AG4303 & 3719 & 3636 & 3015 & 3647 \\
AG5503 & 3718 & 2508 & 2785 & 3657 \\
\hline
\end{tabular}

${ }^{\dagger}$ Means of three replications.
${ }^{\ddagger}$ To compare means within a row or a column $1 s d_{0.05}=200$.
${ }^{{ }_{S}}$ To compare means within a row or a column $l_{s d} d_{0.05}=120$.

in 2011 or 2012 between R3 and R4 (Figure 4(b)). However, in 2011, $C_{i}$ at R5 was greater than the previous growth stages and less in 2012. These differences in $C_{i}$ at R5 again are likely due to differences in maturation of the plants between the two years.

Data from this experiment failed to show any differences in single-leaf CER or related parameters for soybean grown using the ESPS in a humid subtropical environment from what has been reported in other production systems. Previous research $[17,20]$ has found that due to a lack of consistent differences in yields (Table 5) and no cultivar differences in CER or other measured physiological parameters led to the decision of not attempting to relate these physiological data to yield like what was done by Buttery et al., [11]. Data from this experiment does reinforce the importance of temperature in the maturation of soybean. Photosynthesis rates, $g_{\mathrm{sw}}$, and $C_{i}$ all indicate that the plants in 2012 had begun the maturation process by the time these data were 
collected at growth stage R5, though this was not physically visible. Calculating and tracking accumulated GDU 10's when measuring physiological processes in soybean, despite reproductive growth initiation being a photoperiod response, appear to be worthy of further research as a way of better estimating maturity.

\section{Disclaimer}

Trade names used in this paper are solely for the purpose of providing specific information. The mention of a trade name, propriety product, or specific equipment does not constitute a guarantee or warranty by the USDA-ARS and does not imply approval of the named product to exclude other similar products.

\section{Conflict of Interests}

The author declares that there is no conflict of interests regarding the publication of this paper.

\section{References}

[1] L. G. Heatherly, "Early soybean production system (ESPS)," in Soybean Production in the Mid South, L. G. Heatherly and H. F. Hodges, Eds., pp. 103-118, CRC Press, Boca Raton, Fla, USA, 1999.

[2] C. D. Raper and P. J. Kramer, "Stress physiology," in Soybeans: Improvement, Production, and Uses, J. R. Wilcox, Ed., vol. 16 of ASA Monographs, pp. 589-641, ASA, CSSA, and SSSA, Madison, Wis, USA, 2nd edition, 1987.

[3] L. G. Heatherly, "Yield and germinability of seed from irrigated and nonirrigated early- and late-planted MG IV and V soybean," Crop Science, vol. 36, no. 4, pp. 1000-1006, 1996.

[4] G. R. Bowers, "An early soybean production system for drought avoidance," Journal of Production Agriculture, vol. 8, no. 1, pp. 112-119, 1995.

[5] MSUCares, Soybean Production in Mississippi, Mississippi State University Extension Service, Starkville, Miss, USA, 2012, http://msucares.com/crops/soybeans/.

[6] R. H. Bohning and C. A. Burnside, "The effect of light intensity on rate of apparent photosynthesis of leaves of sun and shade plants," American Journal of Botany, vol. 43, no. 8, pp. 557-561, 1956.

[7] W. A. Brun and R. L. Cooper, "Effects of light intensity and carbon dioxide concentration on photosynthetic rate of soybeans," Crop Science, vol. 7, no. 5, pp. 451-454, 1967.

[8] G. M. Dornhoff and R. M. Shibles, "Varietal differences in net photosynthesis of soybean leaves," Crop Science, vol. 10, no. 1, pp. 42-45, 1970.

[9] P. E. Kriedeman, T. F. Neales, and D. H. Ashton, "Photosynthesis in relation to leaf orientation and light interception," Australian Journal of Biological Science, vol. 17, no. 3, pp. 591-600, 1964.

[10] J. E. Beuerlein and J. W. Pendleton, "Photosynthetic rates and light saturation curves of individual soybean leaves under field conditions," Crop Science, vol. 11, no. 2, pp. 217-219, 1971.

[11] B. R. Buttery, R. I. Buzzell, and W. I. Findlay, "Relationship among photosynthesis rate, bean yield and other characters in field-grown cultivars of soybean," Canadian Journal of Plant Science, vol. 61, pp. 191-198, 1981.
[12] H. R. Boerma and D. A. Ashely, "Canopy photosynthesis and seed-fill duration in recently developed soybean cultivars and selected plant introductions," Crop Science, vol. 28, no. 1, pp. 137140,1988

[13] S. W. Ritchie, J. J. Hanway, H. E. Thompson, and G. O. Benson, "How a soybean plant develops," Special Report 53, revised edition, Iowa State University Cooperative Extension Service, Ames, Iowa, USA, 1994.

[14] L. G. Higley, "New understandings of soybean defoliation and their implications for pest management," in Pest Management in Soybean, L. G. Copping, M. B. Green, and R. T. Ress, Eds., Elsevier Science Publications, London, UK, 1992.

[15] L. Zhang, J. Zhang, C. E. Watson, and S. Kyei-Boahen, "Developing phenological prediction tables for soybean," Crop Management, 2004.

[16] G. Bowes, W. L. Ogren, and R. H. Hageman, "Light saturation, photosynthesis rate, RuDP carboxylase activity, and specific leaf weight in soybeans grown under different light intensities," Crop Science, vol. 12, no. 1, pp. 77-79, 1972.

[17] R. M. Gifford and L. T. Evans, "Photosynthesis, carbon partitioning, and yield," Annual Reviews of Plant Physiology, vol. 32, pp. 485-509, 1981.

[18] S. P. Long and J. E. Hällgren, "Measurement of $\mathrm{CO}_{2}$ assimilation by plants in the field and laboratory," in Photosynthesis and Productivity in a Changing Environment: A Field and Laboratory Manual, D. O. Hall, J. M. O. Scurlock, H. R. BolharNordenkampf, R. C. Leegood, and S. P. Long, Eds., pp. 129-167, Chapman and Hall, London, UK, 1993.

[19] H. Kandel and A. Akyuz, "Growing degree day model for North Dakota soybean," NDSU Crop Pest Report, North Dakota State University, Fargo, ND, USA, 2012, http://www.ag.ndsu.edu/cpr/plantscience/growing-degree-day-model-for-north-dakota-soybean-6-28-12.

[20] P. E. Curtis, W. L. Ogren, and R. L. Hageman, "Varietal effects in soybean photosynthesis and photorespiration," Crop Science, vol. 9, no. 3, pp. 323-327, 1969. 


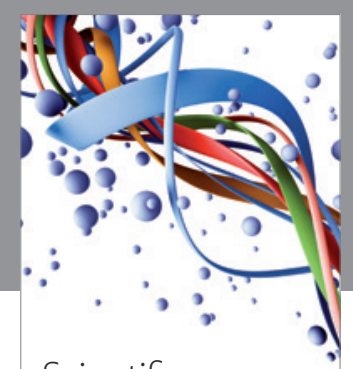

Scientifica
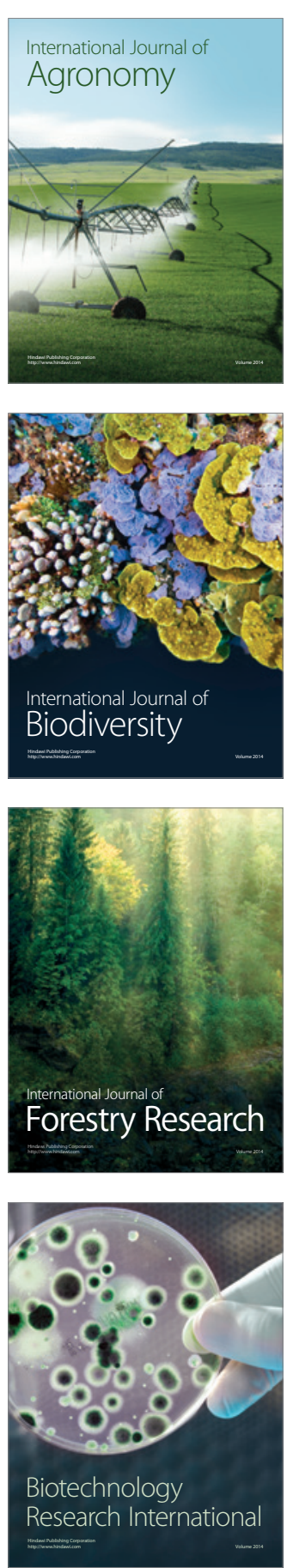
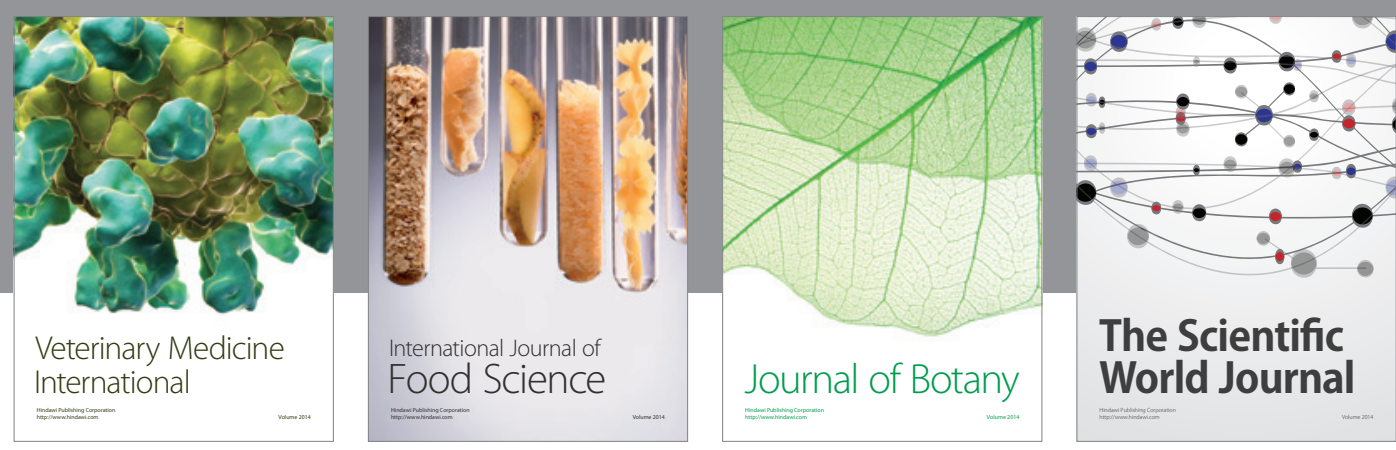

The Scientific World Journal
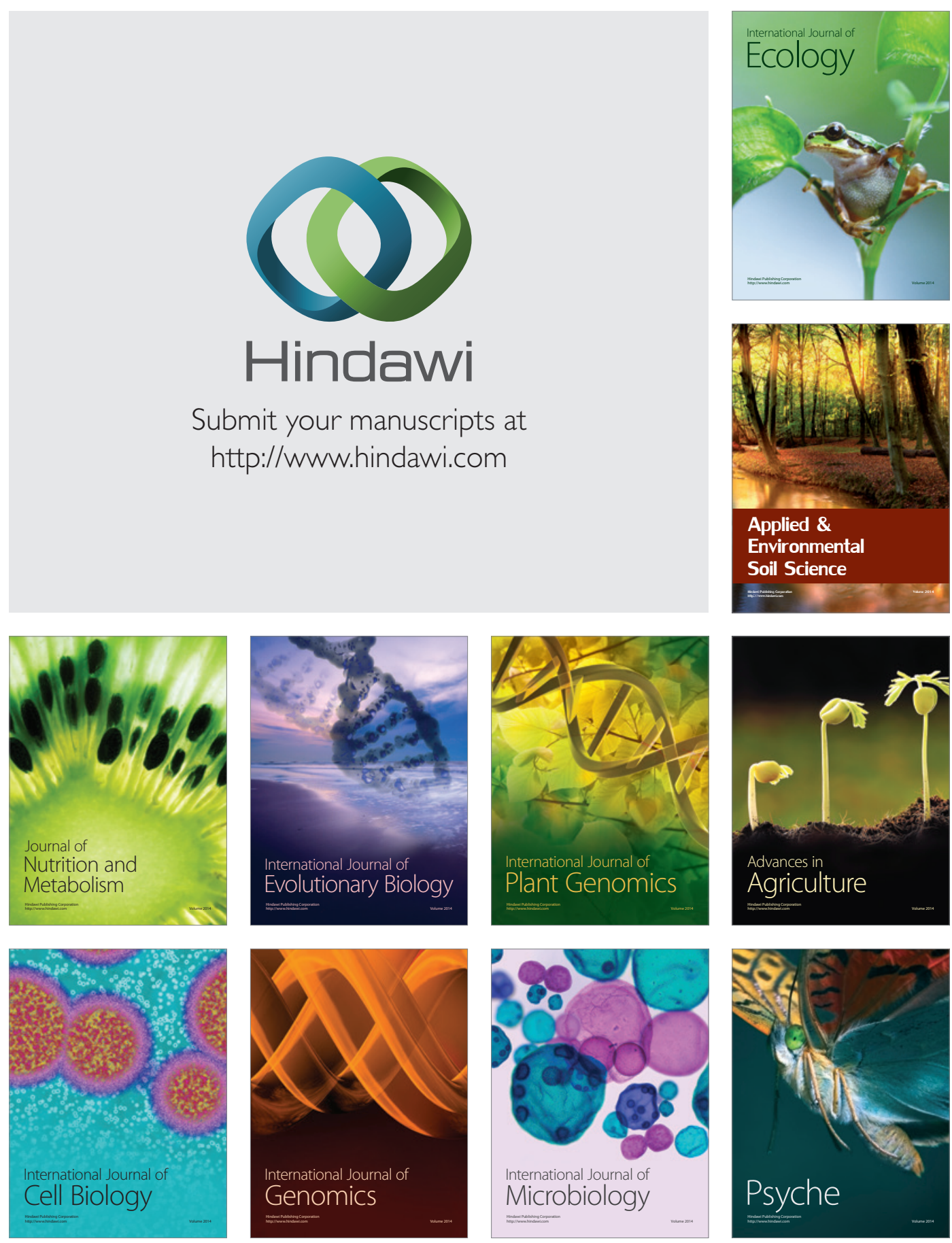